\title{
Vitamin K2: An emerging essential nutraceutical and its market potential
}

\author{
Sunita Aggarwal ${ }^{*}$, Siddharth Gupta ${ }^{2}$, Shalini Sehgal ${ }^{3}$, Praneeta Srivastava ${ }^{1}$, Aparajita Sen ${ }^{4}$, Garishma Gulyani ${ }^{5}$, Anmol Jain ${ }^{2}$ \\ ${ }^{1}$ Department of Microbiology, Institute of Home Economics, University of Delhi, New Delhi, India. \\ ${ }^{2}$ Department of Business Management, Ram Lal Anand College, University of Delhi, New Delhi, India. \\ ${ }^{3}$ Department of Food Technology, Bhaskaracharya College of Applied Sciences, University of Delhi, New Delhi, India. \\ ${ }^{4}$ Department of Genetics, University of Delhi, South Campus, New Delhi, India. \\ ${ }^{5}$ Department of Commerce, Vivekananda Institute of Professional Studies, IP University, New Delhi, India.
}

\begin{tabular}{l}
\hline ARTICLE INFO \\
\hline Article history: \\
Received on: February 17, 2021 \\
Accepted on: June 07, 2021 \\
Available online: February 15, 2022 \\
\hline
\end{tabular}

Key words:

Vitamin K, menaquinones, gut microbiota, nutraceuticals, bone health, hormone

\begin{abstract}
Vitamin $\mathrm{K}$ has recently gained importance as a potential therapeutic agent beyond blood coagulation. Vitamin $\mathrm{K} 2$ is found to be a superior nutrient supplement than $\mathrm{K} 1$. $\mathrm{K} 1$ is mainly obtained from leafy vegetables, whereas $\mathrm{K} 2$ is sourced from fermented products and gut microbiota. However, in contrast to other fat-soluble vitamins, body does not accumulate vitamin $\mathrm{K}$ and depends on $\mathrm{K}$ cycle for its effective use. Vitamin $\mathrm{K} 2$ regulates body calcium metabolism. An insufficient vitamin K2 dose increases the risk of osteoporosis, bone fractures, and cardiovascular diseases. Despite a lot of available literature and also approval by safety regulatory bodies, including Food and Drug Administratio (FDA), its awareness among healthcare professionals and general public is still poor. This understudied nutrient has gained a lot of attention in the market because of its multifaceted role in disease management. Aggressive competition within key sellers is one of the critical factors, which expeditiously upsurge the market growth of vitamin $\mathrm{K}$. The rapid increase in patent applications during the last decade reflects its worldwide recognition as an emerging nutraceutical and hence its future market potential.
\end{abstract}

\section{INTRODUCTION}

Vitamin K also called "Koagulation Vitamin" in Danish, discovered by Henrik Dam and colleagues [1] during studying dietary cholesterol's role. It is a vital fat-soluble vitamin; its alimentation exerts anabolic effect on blood coagulation, bone health, cardiovascular health, and insulin sensitization [2]. Vitamin $\mathrm{K}$ series has long been recognized as a therapeutic agent, particularly vitamin K2 (menaquinones), which has been in clinical use globally for treating brittleness in bones and evidence suggests its role as a transcriptional regulator and a hormone [3]. Recent studies outline the anti-calcification, anti-diabetic, and anti-cancerous roles of vitamin $\mathrm{K} 2$ [4,5].

Furthermore, increased vitamin K2 (VK2) supplementation could decrease not only arterial calcium deposition, but can reverse

*Corresponding Author

Sunita Aggarwal, Institute of Home Economics, University of Delhi, New Delhi, India.E-mail: sunita.aggarwal @ihe.du.ac.in arterial calcification as seen in animal models. Clinical trials prove increased arterial elasticity, healthy bones, and cardiac health by the vitamin $\mathrm{K} 1$ and $\mathrm{K} 2$ supplementation $[5,6]$.

It is difficult to obtain enough vitamin K2 through the usual diet. Fermented food like Natto and Sauerkraut are the only rich source of vitamin $\mathrm{K} 2$, and therefore, there is a need for supplements to meet $\mathrm{K} 2$ demands [7]. As subclinical deficiency of vitamin $\mathrm{K}$ is quite common, adequate intake of $90-120 \mu \mathrm{g} /$ day is proposed for adults, but studies suggest that the amount is insufficient for activation of all vitamin K-dependent proteins or VKDPs. The emerging applications of menaquinones (VK2) necessitate propagating better awareness about the vitamin among healthcare practitioners, the general public, and other stakeholders [8].

The present review is aimed at demonstrating the multifaceted function of vitamin $\mathrm{K} 2$ on human health, including its types, sources, and the emerging market trend. 


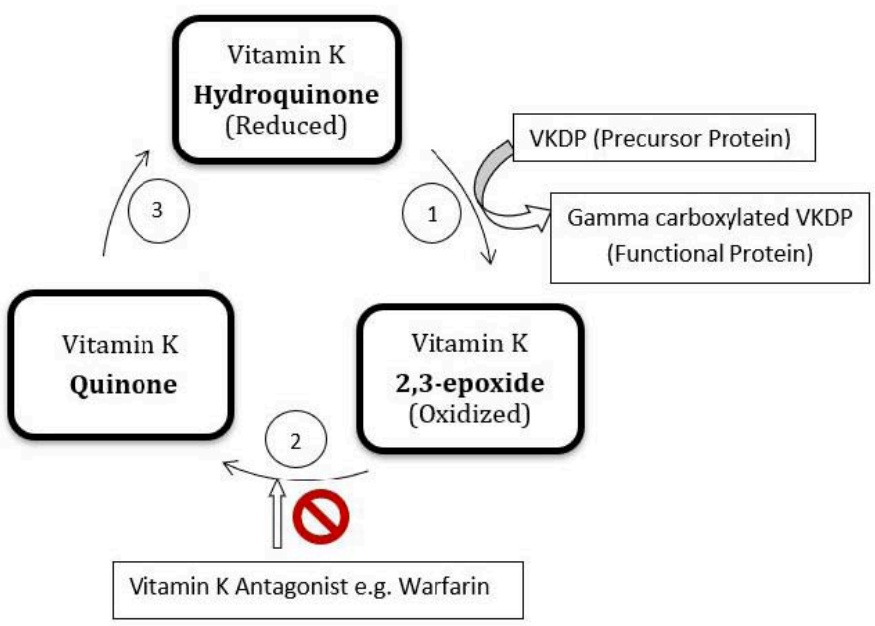

Figure 1: Vitamin K cycle. VKDP: MGP, GRP, OC, Gas6; 1-Vitamin K gamma GGCX; 2-VKOR; 3-Vitamin K reductase.

\section{TYPES OF VITAMIN K}

Naturally, two bioactive forms of vitamin K exist: vitamin K1 (Phytonadione/ phylloquinone ) and vitamin K2 (menaquinones). Although both possess a common ring structure, i.e., 2-methyl-1, 4-naphthoquinone (vitamin K3), they differ in many other aspects (Table 1).

Vitamin K1 is primarily derived from leafy vegetables and fruits. The concentration of phylloquinone in animal tissues is deficient compared to those of the vitamin $\mathrm{K} 2$, which are obtained mainly from animals, fermented products, and gut microflora [9].

There are various isoforms of bacterial menaquinones based on the number of isoprenyl subunits (n), i.e., MK-n, where $n$ can range from 2 to $14[10,11]$. The main type of vitamin $\mathrm{K}(>90 \%)$ present in tissues is Menaquinone-4 (MK-4) which is produced by conversion of phylloquinone/menadione by two possible routes: (a) systemic conversion, in which menadione produced from phylloquinone in intestine/liver undergoes prenylation to form menaquinone- 4 in tissues, and (b) local conversion, in which cleavage and prenylation of menadione occurs within the cerebrum $[10,12,13]$.

Other sources of MK-4 include egg, fish, liver, milk, cheese, and the alteration of long-chain menaquinones (MK-10-MK-13) formed by anaerobes inhabiting the colon. Prolonged use of antibiotics, however, can interfere with this process. Although menaquinones have been put under the general term vitamin $\mathrm{K} 2$, they differ in their origin, availability, and activity [9]. Vitamin K2 can also be formed in the liver through transformation of K3 (Menadione), but FDA has since banned the use of $\mathrm{K} 3$ as a nutritional supplement due to its toxic effects [14].

\section{BIOLOGICAL CYCLE OF VITAMIN K}

The small intestine absorbs vitamin $\mathrm{K}$, which is then transported through the blood to other body parts, including liver. Since the liver uptakes most of the dietary vitamin $\mathrm{K}$ to produce coagulation factors, it causes subclinical vitamin $\mathrm{K}$ deficiency in bones and cartilage unless supplemented [15]. The liver is the main storage organ for both VK1 and long-chain VK2, although a small concentration of MK-4 is also stored in genital organs and pancreas [16]. The human body recycles and reuses the limited amount of vitamin $\mathrm{K}$ stored in the body through vitamin $\mathrm{K}$-epoxide cycle to reduce dependency on a diet [17]. The vitamin $\mathrm{K}$ redox cycle involves the successful conversion of vitamin $\mathrm{K}$ quinone (in diet) to reduced form-hydroquinone, which is then oxidized to vitamin K 2,3-epoxides. The two reactions are facilitated by vitamin $\mathrm{K}$ reductase and $\gamma$-glutamyl transferase, respectively (Fig. 1). The epoxide of vitamin $\mathrm{K}$ recycles to its quinone form through enzymatic action of vitamin $\mathrm{K}$ epoxide reductase (VKOR). Warfarin, an anticoagulant agent, inhibits these reactions [18]. The conversion of vitamin $\mathrm{KH} 2$ to vitamin $\mathrm{KO}$ by $\gamma$-glutamyl transferase is coupled with carboxylation of VKDP at glutamic acid residue catalyzed by glutamyl carboxylase (GGCX).

The long-chain menaquinones have better intestinal absorption when compared to MK-4 and phylloquinone because of their high lipophilicity. Besides, vitamin $\mathrm{K} 2$ has a half-life of a few days in contrast to vitamin $\mathrm{K} 1$ that remains in the blood for only 8 hours [19].

Table 1: Differences between vitamin $\mathrm{K} 1$ and $\mathrm{K} 2$.

\begin{tabular}{|c|c|c|c|}
\hline S. No. & Characteristics & Vitamin K1 & Vitamin K2 \\
\hline 1. & Popularly known as & Phylloquionone & Menaquionone \\
\hline \multirow[t]{2}{*}{2.} & $\begin{array}{l}\text { Structural } \\
\text { differences }\end{array}$ & $\begin{array}{l}\text { Have phytyl side chains consisting of four isoprene } \\
\text { units of which one is unsaturated. }\end{array}$ & $\begin{array}{l}\text { Side chain consists of repeated unsaturated } \\
5 \text {-carbon prenyl units }(4-13) \text {. }\end{array}$ \\
\hline & & Mildly lipophilic. & Long-chain MKs strongly lipophilic. \\
\hline 3. & Location & $\begin{array}{l}\text { Primarily present in plants in association with } \\
\text { chlorophylls }\end{array}$ & $\begin{array}{l}\text { Primarily synthesized by bacteria in food or } \\
\text { by intestinal gut flora. They are associated } \\
\text { with cytoplasmic membrane of bacteria. }\end{array}$ \\
\hline 4. & Sources & $\begin{array}{l}\text { Green leafy vegetables, kale, fruits, broccoli, kiwi, } \\
\text { lettuce, cabbage, spinach, avocado, soybean oil, } \\
\text { canola oil, olive oil, cotton seed oil etc. }\end{array}$ & $\begin{array}{l}\text { Gut bacteria, fermented foods e.g. cheese, } \\
\text { curds and natto, animal products }\end{array}$ \\
\hline 5. & Half life & Short (approximately 8 hours) & Longer (several days) \\
\hline 6. & Storage & Mainly stored in liver & Distributed extensively in body \\
\hline 7. & $\begin{array}{l}\text { Affinity to } \gamma \text {-glutamyl } \\
\text { carboxylase }\end{array}$ & Low & Higher than vitamin $\mathrm{K} 1$ \\
\hline
\end{tabular}


Table 2: Sources of vitamin K2.

\begin{tabular}{|c|c|c|c|}
\hline $\begin{array}{l}\text { S. No. } \\
1 .\end{array}$ & \multicolumn{2}{|c|}{ Type of menaquinone } & $\begin{array}{l}\text { Dietary sources } \\
\text { - All products (except buckwheat, } \\
\text { black bean natto, and hikiwari natto) }\end{array}$ \\
\hline 1. & Small chain & MK-4 & $\begin{array}{l}\text { - All products (except buckwheat, } \\
\text { black bean natto, and hikiwari natto) } \\
\text { - Non-dairy fermented products } \\
\text { - Egg } \\
\text { - Few species of fish }\end{array}$ \\
\hline 2. & Long chain & MK-6-MK-10 & $\begin{array}{l}\text { - Offal like liver, kidney } \\
\text { - Fish: eel, plaice } \\
\text { - Sour milk, buttermilk, curd }\end{array}$ \\
\hline & & $\begin{array}{l}\text { MK-9 (predominantly) } \\
\text { MK-8 }\end{array}$ & - Dairy products \\
\hline & & $\begin{array}{l}\text { MK-7 (very high concentrations) } \\
\text { MK-10 }\end{array}$ & $\begin{array}{l}\text { - Fermented plant products } \\
\text { - Cheese: hard, semi-hard, and soft }\end{array}$ \\
\hline
\end{tabular}

\section{SOURCES OF VITAMIN K2}

The edible fermented products like dairy products, cheese, nattos, cheonggukjang, etc., are the key sources of vitamin K2. The microorganisms in the gut, mainly bacteroides, do produce some amount of vitamin K2 inside the body (Table 2). The bacterial MKs acts as an electron carrier and facilitates the molecular transport in sporulation and across the cell membrane [20]. A number of bacterial species can carry out the fermentation of food, but little information is available on growth conditions required and the number of individual menaquinones produced. The type of MKs formed depends on the bacterial strains and the raw material used, e.g., high amounts of long-chain MKs are present in dairy products but are quite low in animal products. Song et al. [21], in their study, revealed that by mutating the Bacillus subtilis strain and optimizing the fermentation condition, vitamin $\mathrm{K}$ production was increased sufficiently. Wu and Ahn [22] found maltose, tryptone, and glycerol as the key components in medium that enhanced the MK-7 production in static cultures.

Ren et al. [23] reviewed three different types of vitamin K2 production via extraction, chemical and microbial production. The lactic acid bacteria like Lactobacillus, Streptococcus, Leuconostoc, and Lactococcus secretes an array of long-chain MKs [24]. Lactococcus lactis strains are found to produce high amounts of long-chain MKs. Lactobacillus and Streptococcus, important starter cultures in fermented foods, however, do not produce detectable levels of MKs. "Natto" produced by B. subtilis is another potential candidate providing a high amount of MKs (MK-4-8), particularly MK-7 [22-25]. Although many fermented foods like natto contain high amounts of MKs, there is a need for the industrial production of vitamin $\mathrm{K}$ to be used for therapeutic purposes. More thorough investigations are required to search for high producers and employ genetic manipulations and optimize the conditions for production of high amounts of vitamin K2. Some of the important bacteria producing different forms of vitamin $\mathrm{K} 2$ (menaquinones) are listed in Table 3.

The individual amount of $\mathrm{PK}$ and different forms of $\mathrm{MKs}$ in various food products is unknown. As reviewed by Walther et al. [26] only 7 of the 30 databases on National Food Consumption mentioned vitamin $\mathrm{K}$ content. Also, the amount can vary with the production process and dietary consumption pattern. MK synthesis seems to occur by two pathways, shikimate pathway commonly used by obligate/facultative aerobes and futalosine pathway prevalent in anaerobic bacteria. The fact that humans lack futalosine-dependent pathway makes it a potentially important target for assessing the inhibitors of this biosynthetic pathway for the development of new drugs $[22,23]$.

Menaquinones, however, are not produced by molds and yeasts. Despite the production of large amounts of MKs by gut bacteria, only little is functionally available, reason being, it is mainly produced in distal colon while the main absorption site is terminal ileum where bile salts carry out its solubilization. Absorption of vitamin $\mathrm{K}$ depends on its lipophilicity. Recent studies have highlighted the need for vitamin $\mathrm{K} 2$ intake, since intestinal menaquinones may not be sufficient.

\section{BIOLOGICAL ACTIVITY OF VITAMIN K SERIES}

Vitamin $\mathrm{K}$ being a multifunctional vitamin has assumed a significant position in various processes such as coagulation of blood, prevention of calcification in blood vessels, signal transduction, etc. Vitamin $\mathrm{K}$ is a cofactor for enzyme GGCX that carboxylate glutamate into $\gamma$-carboxyglutamate and posttransnationally modified many VKDPs. The biologic activities differ with the types and subtypes of vitamin K. Vitamin K2 has better nutraceutical potential than its counter isoform [27]; however, awareness needs to be created among practitioners and the public.

Researchers theorized that persistent vitamin $\mathrm{K}$ deficiency is an admonition for the rapid progress of an array of age-related ailments, viz. osteoporosis, diabetes, cancer, cardiovascular, neurological, and pulmonary diseases [28,29].

\subsection{Blood Coagulation}

Blood coagulation is a process that involves activation of about 12-13 blood-clotting factors, of which 7 factors are VKDPFactor II, VII, IX, X, protein $\mathrm{S}$, protein $\mathrm{X}$, and protein $\mathrm{Z}$. VK1 
Table 3: Microorganisms involved in vitamin K2 production.

\begin{tabular}{lll} 
Location & Microorganisms producing menaquionone & $\begin{array}{l}\text { Isoforms types of vitamin } \\
\text { K2 produced }\end{array}$ \\
Human gut & Bacteroides & MK-10, MK-11 \\
& Eubacterium lentum & MK-6 \\
& Vellionella & MK-7 \\
& Enterobacter and intestinal flora & MK-8 \\
Fermented food & Lactococcus & MK-7-MK-9 \\
& Leuconostoc & MK-7-MK-10 \\
& Propionibacterium & MK-9 \\
& Lactobacillus fermentum LC272 & MK-4 \\
& L. lactis YIT 3001 & MK-9 and MK-10 \\
& B. subtilis natto & MK-7 \\
& Lactobacillus lactis ssp. cremoris YIT2011 & MK-8 and MK-9 \\
\hline
\end{tabular}

in the liver modulates the synthesis of vitamin K-dependent coagulation proteins. The post-translational modification of these seven VKDPs makes them bind calcium [30].

Excessive vitamin intake is not responsible for abnormal clotting. Some people are at an increased risk of thrombosis that can move to the heart or brain, resulting in a heart attack or a stroke. Individuals can also suffer from a condition called embolism in which a blood clot travels around the body and lodges in an organ. Some oral anticoagulants (vitamin $\mathrm{K}$ anticoagulants) like warfarin are available that interfere with the vitamin $\mathrm{K}$ cycle through inhibiting vitamin $\mathrm{K}$ 2,3-epoxide reductase activity, resulting in limited gamma-carboxylation of VKDPs involved in coagulation and thus obstructs hemostasis. In case of excessive thinning of blood or to counteract the effect of warfarin just prior to surgery, vitamin $\mathrm{K}$ can be given to the patients [31].

\subsection{Bone Health}

A bone undergoes continuous revamping, and every 8-10 years, good bones replace the human skeleton. This continuous revamping is due to equilibrium between formation of bones, their resorption, and turnover. Vitamin K2, along with vitamin D3, is emerging as a leading protagonist in maintaining bone homeostasis and involved in regulation of calcium [32].

Obesity is a factor of osteoporosis. The increasing trend of obesity is found to be coupled with deficiency of vitamin $\mathrm{K}$ in adults. The deterioration of bones due to obesity could be reversed with supplementation of vitamin $\mathrm{K}$ by modulating the activities of osteoclasts and osteoblasts [32]. In the bones, osteocalcin (OC), a calcium ion-binding vitamin $\mathrm{K} 2$-dependent protein, is produced by osteoblasts. It has two major domains: one calcium-dependent "Gla helix" that binds with hydroxyapetite, the major component of bone matrix, and another "-COOH-terminal beta sheet" which attracts monocytes, the imputed precursor of osteoclasts. The VK2dependent carboxylation of OC at three gamma-carboxyglutamic acid residues by GGCX allows calcium ion binding.
Chronic deficiency of vitamin $\mathrm{K} 2$ can result in under-carboxylation of $\mathrm{OC}$ and other gamma-carboxyglutamic acid proteins, thus enhancing the proneness to osteoporosis $[33,34]$.

With aging and under certain pathological conditions such as osteoporosis, there is a rapid increase in bone turnover that disrupts the constant bone remodeling and eventually causes a decrease in BMD. The silent osteoporotic disease progression involves the manifestation of weak and brittle bones where even a minor fall or coughing can result in bone fracture. It affects men and women of all races, but white and Asian women are more prone to this disease, especially older women postmenopause [34,35]. Singh [36] observed an inverse relationship between BMD and OC serum levels in postmenopausal females. Another VKDP involved in bone remodeling and metabolism is matrix Gla protein (MGP). The level of post-translationally modified MGP modulates the Wnt/ $\beta$-catenin signaling pathway. Studies have shown that MGP may regulate osteoporosis pathogenesis, owing to its role in bone calcification and osteoclast differentiation $[3,37]$.

Vitamin K's role in fracture risk is yet to be proven. The importance of vitamin $\mathrm{K}$ supplementation in managing the fracture risk and bone health requires additional research because of the bias associated while measuring its impact on bone mass density (BMD), the short time involved in assessment, and the correct customization of the cofounders.

Classically, vitamin D and calcium were used as supplements to maintain bone health but their role in vascular calcification made clinicians look for other alternatives. Vitamin $\mathrm{K}$ intake, particularly $\mathrm{K} 2$, reduces the chances of osteoporosis and vascular calcification. A $35 \%-40 \%$ reduction in bone loss at the femoral neck and improvement in BMD was noted among postmenopausal women on combined supplementation of vitamin K2 with calcium and vitamin D3 $[35,38]$. It decreases the rate of decline in BMD and also successfully reduces the non-spinal (81\%), spinal $(60 \%)$, and hip fracture (77\%) [39]. Japan and some other countries are now officially recommending dietary vitamin $\mathrm{K} 2$ as a supplement for osteoporosis $[40,41]$. 
The hormonal function of $\mathrm{OC}$ in the modulation of glucose metabolism has been indicated using genetically modified OC mouse, speculating the role of vitamin $\mathrm{K}$ as the modulator of the pancreas-bone axis [2]. The vitamin K-deficient bone has low tissue and serum OC concentrations, resulting in diabetes mellitus and glucose intolerance. Extensive research is needed to obtain more conclusive evidence and mechanistic insight regarding the correlation of vitamin $\mathrm{K}$ insufficiency and in bone health, insulin secretion, and sensitivity and, therefore, to establish a new platform for therapeutic intervention of vitamin $\mathrm{K}$ in metabolic disorders.

\subsection{Cardiovascular Diseases (CVDs)}

Deposition of calcium usually occurs in bones, but under certain abnormal conditions it can also get incorporated in soft body tissues. It has been found that calcium and phosphate ions in the extra-hepatic tissues form calcium phosphate that sometimes sticks to fatty deposits present on the walls of blood vessels causing vascular calcification and proneness to CVDs. Vitamin K deficiency or high calcium/vitamin D ratio is the cause of vascular calcification [42].

Studies have revealed that VK2, and not VK1 supplementation, decreases arterial calcification and Coronary Heart Disease (CHD). Aortic calcification and MK intake are inversely correlated [43]. This condition can be associated with kidney diseases, diabetes, hypertension, and advanced age with blocked arteries and blood clots. Patients with chronic kidney diseases are at a high-risk vascular calcification and prone to CVD, thus predisposing the patients to death [44]. A large number $(\sim 57 \%-83 \%)$ of patients on dialysis were found to have coronary artery calcium (CAC) as compared to healthy individuals $(\sim 13 \%)$ without any renal diseases [45].

Out of the 17 Gla proteins, MGP is the well-studied VKDP, which obstructs vascular calcification implicated in CVDs. Recently, subclinical vitamin $\mathrm{K}$ deficiency was reported to have implications in Chronic Kidney Diseases (CKD). Studies have found that in $\mathrm{CKD}$ patients, vitamin $\mathrm{K} 2$ intake lowers the dephosphouncarboxylated (dp-uc) MGP levels. Reestablishment of kidney functions is noted after the establishment of adequate vitamin $\mathrm{K}$ levels [46]. More thorough and interventional studies must be carried out to understand the exact role of MGP and implications of vitamin $\mathrm{K} 2$ supplementation in $\mathrm{CKD}$ and CAC in patients on hemodialysis [47]. Scientists have proposed the effective role of MK-7 in modifying OC and other VKDPs and hence its function in soft tissue calcification $[47,48]$.

Besides MGP, other VKDPs like OC, Gla-rich proteins (GRP), growth arrest-specific-6 (Gas6), and periostin regulate/prevent the process of soft tissue calcification through their gamma carboxylation assisted by vitamin K (Fig. 5) [44,49,50]. Gas6 protein obstructs the endothelial and smooth muscle cell calcification via preventing apoptosis. Periostin present in the heart has a shielding effect against vascular calcification. However, under subclinical levels of Vitamin K2, all these proteins failed to get carboxylate, thus increasing the risk of arterial calcification and CHD. Administration of oral anticoagulants also increases risk of calcification of arterial wall by impairing calcium- regulating activity of MGP [44]. MK-7 has been seen to decrease the prevalence of aortic stenosis in the elderly [48].

Recent in-vivo and in-vitro experiments in CVD have highlighted the anti-inflammatory function of vitamin $\mathrm{K}$ and an inverse relationship between "inflammatory markers" and circulating vitamin K levels [32,49].

Although various experiments have shown the positive effect of vitamin $\mathrm{K}$ dosage in preventing vascular calcification, its role is poorly understood in CKD and dialysis cohorts [51]. Hence, more epidemiological and experimental studies need to be carried out to entrench the function of vitamin $\mathrm{K}$ supplementation in cardiovascular health.

\subsection{Diabetes mellitus}

Diabetes mellitus is a common lifestyle ailment that affects not only adults but children too and its incidence has increased in recent years. The disease is associated with a number of microand macro-vascular and other serious complications such as bone demineralization, decreasing quality of life, and increasing mortality.

Vitamin K2 was reported to enhance the insulin sensitivity, control the glycemic index, and reduce the type 2 diabetes mellitus risk through different mechanisms; the important ones involved being the incretin effect, post-translational modification of VKDP, and obstruction in inflammation [52,53]. Vitamin K2 was more effective as compared to vitamin $\mathrm{K} 1$ in suppressing the incidence of type 2 diabetes [54].

Recently, studies involving various mouse cell lines indicated the role of MK-4 as an incretin-like agent. Multiple studies have shown the importance of incretin-dependent therapeutic targets in lowering the blood glucose level [52].

Researchers have suggested OC, MGP, and Gas6 as three major VKDPs involved in diabetes mellitus pathogenesis. In subsequent studies, the upregulation of gene expression of OC and decrease in the severity of diabetes mellitus and obesity was observed on vitamin K2 supplementation [55]. The carboxylated osteocalcin (cOC) reported to have the direct proliferative effect on mouse beta-cells and suggested to have functions as an endocrine hormone in humans [56]. Vitamin K2 modulates glucose sensitivity through carboxylating $\mathrm{OC}$ by suppressing the release of those cytokines Interleukin (IL)-1 $\beta$, IL-6, and Tumor Necrosis Factor- alpha $(\mathrm{TNF}-\alpha)$ that increases insulin resistance [49]. Additional findings suggested that while studying the energy metabolism and its effect, one should not only measure $\mathrm{OC}$ concentration, but also consider the ratio of uncarboxylated $\mathrm{OC} /$ total $\mathrm{OC}$ or the $\mathrm{cOC} /$ uncarboxylated OC [57].

Type 2 Diabetes mellitus (T2DM) is characterized by prolonged low-grade inflammation and protein Gas6 is also linked with inflammatory processes. In an Asian cohort, it is shown that the genetic variants of Gas6 proteins independent of Gas6 protein levels are related to insulin resistance or diabetic status. Present data do not provide any conclusive evidence about the role of Gas6 in T2DM. Evidence has shown vitamin K's ability to prevent 


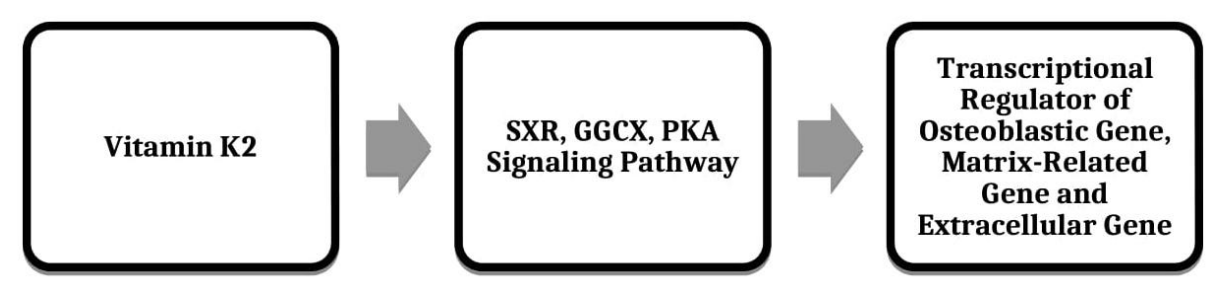

Figure 2: Function of vitamin $\mathrm{K} 2$ as hormone.

inflammation, which will modulate insulin sensitivity, secretion, and glucose levels $[52,57]$.

Identifying the molecular mechanism linking the VKDPs and glucose metabolism will help scientists to explore new therapeutic avenues in the treatment of Diabetes mellitus and other related disorders. More observational experiments and interventional trials are required to assess the possible therapeutic effect of vitamin $\mathrm{K}$ on DM.

\subsection{Vitamin K2 as a Hormone}

If we analyze a basic hormone action, then it is a signal molecule that receives a signal and subsequently activates transcription factors and regulates specific gene function, in turn, switching on a complex network of pathways away from the site of its production. During the last decade much of the evidence has been obtained which justify vitamin K2 as a hormone (Fig. 2). It was reported that MK-7, a K2 analogue, was even able to substitute insulin, some growth factors, and interleukins.

Vitamin K2 acts as a transcriptional regulator or modulator and can upregulate the expression of number of genes for markers of bones, cell phenotype, and proteins involved in cell signaling and extracellular matrix proteins, by binding with steroid and xenobiotic receptor (SXR) — an intra-nuclear receptor [3].

Ichikawa et al. [58] identified two novel target genesStanniocalcin-2 (STC-2) (stanniocalcin) and growth differentiation factor-15-in osteoblastic cells, the upregulation of which by MK-4 seems to occur through protein kinase A (PKA) regulatory signaling mechanism. MK-7 and vitamin K1 were incapable to induce these [59]. In another study, MK-7 was found to have a stimulatory effect on the secretion of various molecules like OC, IL-7, Transforming Growth Factor- Beta (TGF- $\beta$ ), Osteoprotegerin (OPG), and Receptor Activator of Nuclear Factor Kappa-B Ligand (RANKL )(osteoclast markers) from osteoblasts. The stimulatory effect was again mediated through the SXR receptor. Moreover, like insulin and growth factors, these vitamin K2 analogues (MK7 and MK-4) can upregulate target genes' expression by activating transcription factors of the Fox A and Fox O family [3].

The testosterone production was also found to increase by Vitamin $\mathrm{K} 2$ via upregulation of the testosterone producing genes expression in testes (Fig. 3). In vitro administration of MK-4 stimulates the synthesis of CPA11A enzyme that catalyzes the rate limiting transformation of cholesterol to testosterone in testes $[59,60]$.

\subsection{Spermatogenesis Regulation}

Usually, the male gonads exhibit a very high rate of metabolic activity compared to other organs. This leads to the development of oxidative stress within the testes. This oxidative stress ultimately leads to the formation of unusual gametes, decreases sperm count, and increases the disintegration of gamete's DNA. Vitamin K rescues the testes from oxidative stress via its antioxidant property. Sanyaolu et al. [61] has shown that both vitamin K isoforms can significantly impact the testes as an antioxidant and vitamin $\mathrm{K}$ insufficiency in diet results in impairment of spermatogenesis.

Experimental data using a mouse model lacking the gene of GGCX specifically in Sertoli cells exhibited a decrease in the sperm count and movement and apoptosis in germ cells within malformed seminiferous tubules. Shiba et al. [62] established that spermatogenesis stimulation occurs due to enhanced enzymatic function of GGCX in the Sertoli cells. There is a need for further investigations to understand the underlying mechanisms involved in reducing male infertility through Vitamin K supplementation.

\subsection{VK2 in Oncogenesis}

The similarity between the basic structure of VK and certain chemotherapeutic drugs partially qualifies the VK2 as an anticancer agent. Popa et al. [63] highlighted some in-vitro, as well as

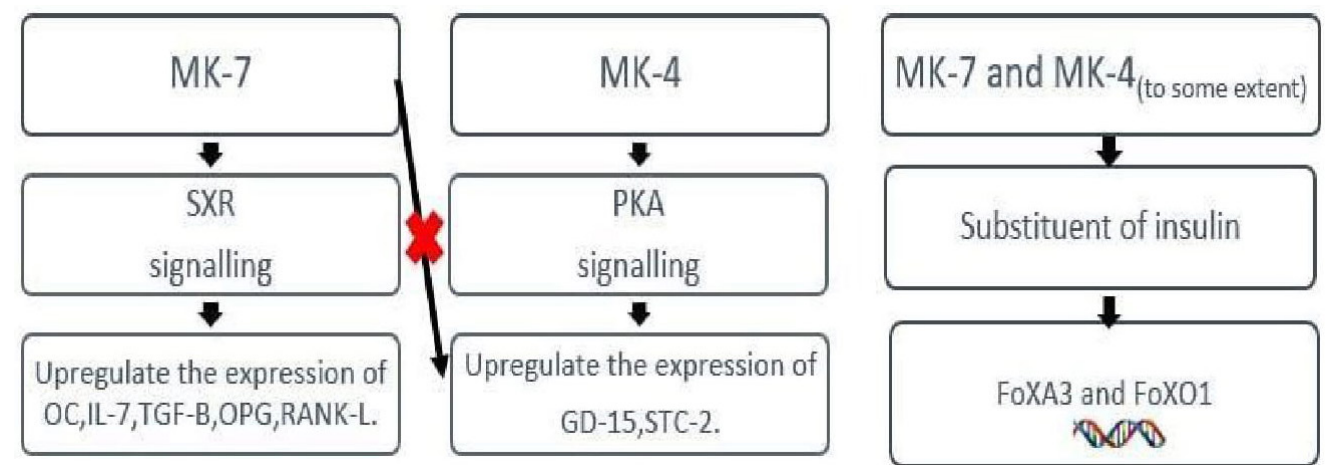

Figure 3: Influence of vitamin K2 isoforms on various target genes. 


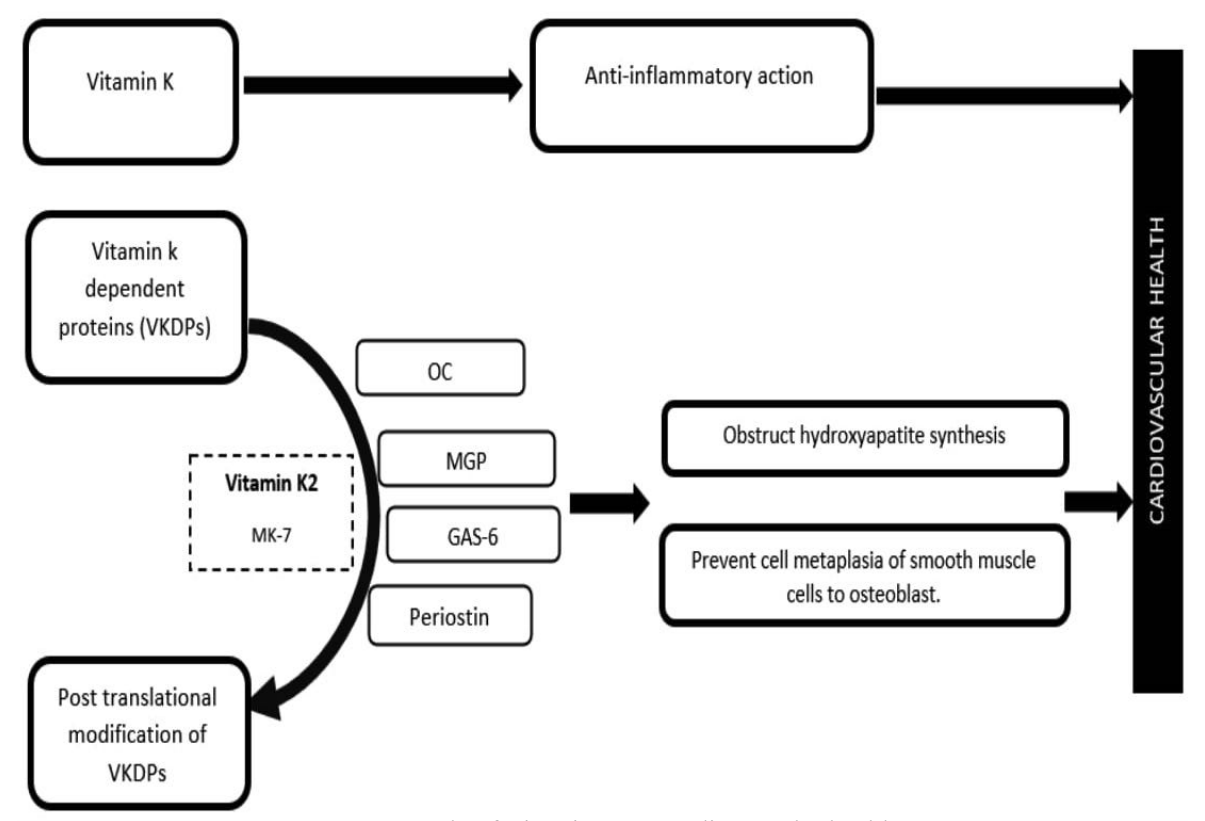

Figure 4: Role of Vitamin K on cardiovascular health.

interventional studies, which demonstrated the anticancer property of VK2 in various cancer cell lines. The liver cancer threat was significantly reduced $(\sim 20 \%)$ in patients with viral cirrhosis on intake of vitamin K2 [62]. Beaudin et al. [65] reported that while K1 treatment to triple negative breast cancer cells enhance cell growth, K2 had anti proliferative effect.

The anti-oncogenic vitamin K2 activity can be partly explained by its redox cycle [66]. Reactive oxygen species (ROS) and reducing equivalents [glutathione, Nicotinamide Adenine Dinucleotide Phosphate Hydrogen (NADPH), and Nicotinamide Adenine Dinucleotide Hydrogen (NADH)] are usually implicated in the maintenance of cancer cell homeostasis. Multiple in-vitro studies have stated that during the $\mathrm{VK}$ redox cycle, these oncogenic cofounders are consumed by VK2.

Recent studies have highlighted the involvement of different molecular mechanisms in various inhibitory effects of VK2 on cancerous cell lines. These include inhibition of cell cycle proliferation, inhibiting cell differentiation, preventing invasion, inducing apoptosis, reducing inflammatory signals, and promoting autophagy in cancer cells $[63,67]$. The cell proliferation is inhibited by targeting signaling pathways involving translocation of transcription factor Nuclear Factor Kappa B (NFкB) to nucleus, activating PKA phosphorylation and suppressing expression of the protooncogene c-MYC and hepatoma-derived growth factor gene [4]. More experimental studies are, however, needed to clarify the model for PKA phosphorylation via VK2.

In recent experiments, cancer cells were found to be prone to death via mitochondria-related apoptosis through the ROS$\mathrm{JNK} / \mathrm{p} 38 \mathrm{MAPK}$ regulatory signaling pathway. Initially VK2 depolarizes the mitochondrial membrane and through stimulation of caspase-3 initiates programmed cell death [4,53]. Cancer cells utilize oxygen quickly during metabolic activities making them vulnerable to vitamin $\mathrm{K} 2$ mediated oxidative stress killing [68]. VK2 pro-apoptotic effect and mitochondrial programmed cell death are involved in the inhibition of oncogenesis. VK2 downregulates the transcription of matrix metalloproteinases that regulate tumor metastasis and invasion via the inhibition of $\mathrm{NF} \kappa \mathrm{B}$ and AP-1 genes [4].

Studies reveal that in various cancer cells, VK2 shows anti-cancer activity via promoting autophagy. It is found that overexpression of Bcl-2 may switch the anti-cancer activity of VK2 from apoptosis to autophagy [69]. Duan et al. [70] were the first to show increased glycolysis through promoting glucose consumption by vitamin K2 that triggered metabolic stress and cell death by (AMP-Activated Protein Kinase) AMPK-dependent autophagy in bladder cells

The comprehensive mechanism behind vitamin K2 anticancer activity is still not very clear. Further research is needed to potentiate the function of VK2 in cancer therapy and its use synergistically with other chemotherapeutic drugs.

\subsection{Cognition and Brain Health}

The aging population is at a significant risk of acquiring neurodegenerative disorders, depression, and anxiety. Vitamin K is proposed to have a significant role in cognitive health during aging, particularly MK-4 that is found to be predominant in the brain $[63,71,72]$. Moreover, scientists identified the number of VKDPs viz. protein C, S, Gas6 and OC which are actively involved in cognitive functions [71]. While protein $\mathrm{C}$ and $\mathrm{S}$ possess cytoprotective activity, Gas6 is involved in cell homeostasis. Recently in vivo studies on protein $\mathrm{S}$ have emphasized their role in the modulation of neuronal health and the blood-brain barrier (Fig. 4). Post-translationally modified form of OC is involved in maintaining bone and brain homeostasis and alleviates symptoms of depression and anxiety, supporting its role in cognition and the synthesis of monoamine neurotransmitters. OC's role as a prospective anti-aging molecule, however, needs further investigation. The Gas6 aids in neuronal survival and maintenance via mitogen-activated protein kinase-signaling pathway (MAPK). 


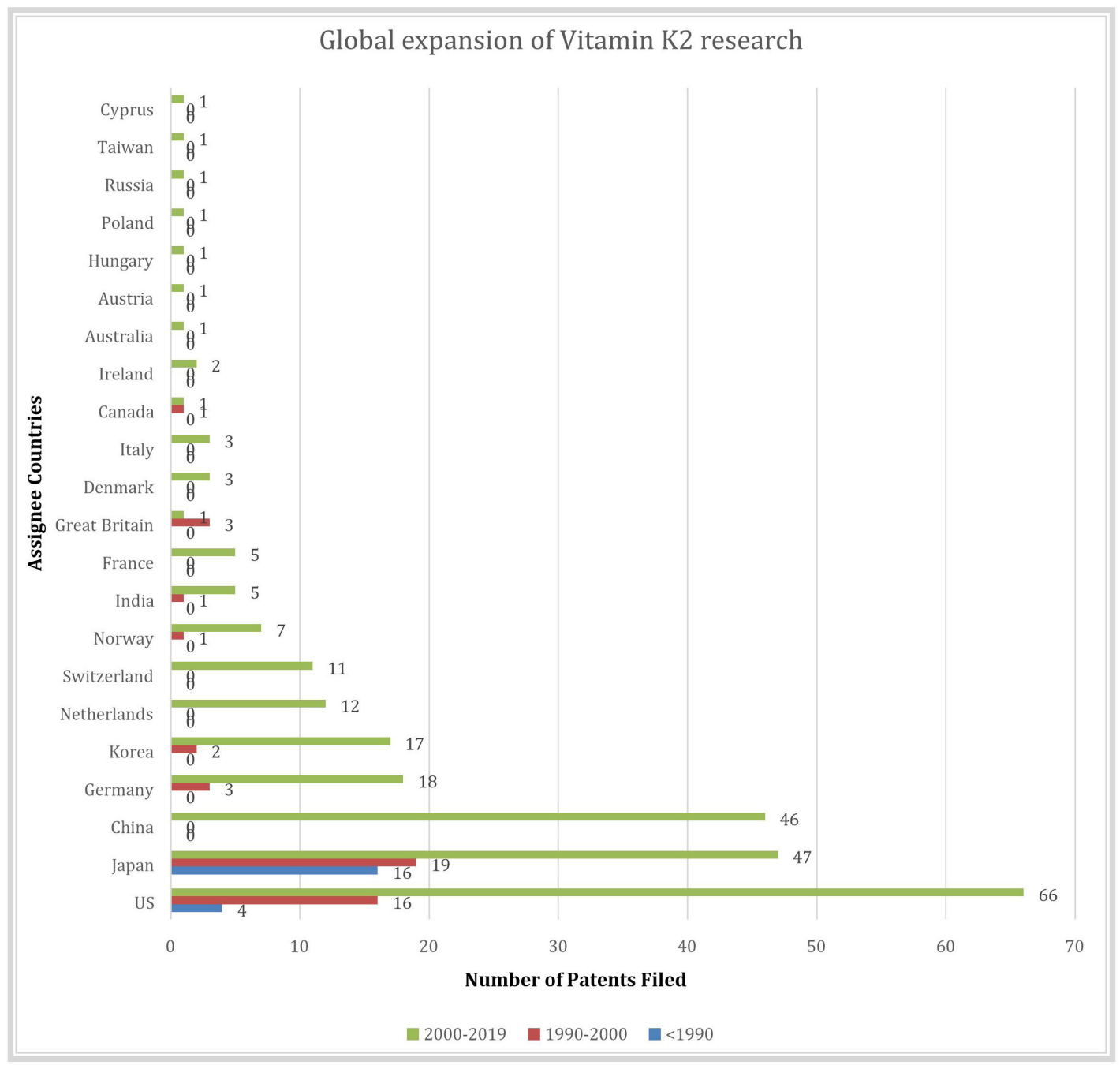

Figure 5: Global expansion of vitamin K2 research over three decades.

A study in rodents by Gancheva and Zhelyazkova-Savova (2016) showed the decrease in progression of symptoms like anxiety and depression found to be associated with metabolic syndrome, with vitamin K2 supplementation [73].

Aging-related neurodegeneration is a characteristic of Parkinson's and Alzheimer's diseases (ADs) also [74,75]. Yu et al. [75] highlighted the lower levels of VK2 in patients who have Parkinson's disease than the controls; the pathogenesis may be contributed/due to dysregulation of inflammatory response and mitochondrial dysfunction. $\mathrm{AD}$, leading to loss of memory and cognitive function, is reported to occur due to Amyloid- $\beta(A \beta)$ accumulation and neural cell death. Number of studies demonstrated the protective role of vitamin $\mathrm{K} 2$ in inhibiting A $\beta$ cytotoxicity, caspase- 3 induced apoptosis and by rescuing mitochondrial dysfunction $[75,76]$. However, to potentiate the antiAlzheimer's and anti-Parkinson's role of VK2, more elaborate human trials/intervention studies are needed.

Tanprasertsuk et al. [77] found that in centenarians regardless of its functional status in cognition, cerebral MK-4 is independent of circulating phylloquinone concentration. Although the mechanistic insight into vitamin $\mathrm{K}$ movement across the blood-brain barrier is yet to be exhibited, scientists have hypothesized that brain tissues convert the circulating vitamin $\mathrm{K} 3$ or phylloquinone into MK-4.

Vitamin K2 plays a modulatory role in brain function and sphingolipid metabolism [78]. Its importance is also shown in inflammation and oxidative injury. Given the severity and the surge of neurodegenerative ailments in the aging population, it is extremely important to conduct more experimental and human studies to evaluate vitamin $\mathrm{K}$ biomarkers and optimized concentration involved in maintaining brain health and cognition.

\subsection{Pulmonary Disease and COVID-19}

Emphysema and chronic bronchitis are implicated in chronic obstructive pulmonary disease. Recently scientists reported the synergistic action of vitamin $\mathrm{K}$ and vitamin A can slow down the progression of emphysema and improve pulmonary health [79]. 
Recent clinical studies of COVID-19 cases have also highlighted the positive impact of vitamin $\mathrm{K}$ supplementation in the reduction of mortality rate. While the majority of patients have mild symptoms, few develop coagulopathy and thromboembolism and suffer with respiratory failure (trial clinical). The level of vitamin $\mathrm{K} 2$ measured by inactive forms of MGP i.e dp-uC MGP was low in COVID-19 patients with poor prognosis [80]. Janssen et al. [81] reviewed the sequential mechanism behind pulmonary and thrombotic damage implicated in pneumonia-induced vitamin K deficiency. Acute lung injury is related to cytokine storm and the VKDP protein $\mathrm{S}$ is involved in suppressing the cytokine storm by inhibiting the synthesis of inflammatory cytokines. Due to vitamin K deficiency, decreased levels of the activated protein S and MGP may increase the progression of thrombosis and lung damage $[63,82]$.

Goddek [83] indicated the synergistic action between vitamin D3 and $\mathrm{K} 2$ in reducing mortality in COVID-19 patients. However more systematic randomized clinical studies have to be conducted to assess the synergistic effect of these vitamins in management of COVID-19 infections.

Further, cardiovascular manifestations like myocardial injury, thromboembolism are commonly associated with COVID-19 [84]. These may be the outcome of insufficiency of vitamin K2 that prevent the activation of VKDPs involved in preventing soft tissue calcification.

The prospective role of vitamin $\mathrm{K}$ intake in inhibiting COVID-19 progression or improving the pulmonary and heart functions in patients recovering from the COVID-19, however, needs more investigation.

\section{PROSPECTIVE MARKET POTENTIAL OF VITAMIN K2}

Vitamin $\mathrm{K}$ series is now recognized as an essential nutraceutical beyond blood coagulation. Today, vitamin K2 has carved its unique niche among food supplements as its application arena has extended to the management of present-day lifestyle diseases like osteoporosis, arteriosclerosis and diabetes. Therefore, the market potential of vitamin $\mathrm{K} 2$ is expanding and is expected to increase rapidly since drugs used for management of these diseases have the largest market sector $[85,86]$. Further, regulatory status of vitamin K2 shows that it is safe without any known toxicity [87]. MK-7, the most versatile vitamin K2 is now approved by FDA, Japan and European regulatory bodies [88]. With these global safety approvals, a leap has been observed in the number of patent applications and the assigning countries worldwide.

A preliminary patent survey was conducted on the Questel Orbit Database. Nearly 300 patent applications were found. These were comprehended to get a glance of trends in protected intellectual properties on vitamin K2 worldwide over the last three decades. The patents were found to be process patents involving microbial processes and also the application patents indicating its usage in healthcare. The trends reveal its initiation in Japan in the early eighties but later US also took lead and major researchers are still being reported from US and Japan. China, Korea and Germany have filed more than twenty patents in the present decade. If decade wise analysis is carried out, then major worldwide growth can be observed during the present decade (Fig. 5). These trends do indicate that the area of research on vitamin K2 is growing rapidly and is relatively new which depicts the growth of its market in near future. Some of the lead companies are Fuji oil, Invista, Torquin, Pharmaco, NattoPharma etc.

Global vitamin K2 market was observed through various web links $[89,90]$. It was seen that North America, Latin America, Central and Eastern Europe, Western Europe, Middle East, Africa, and Asia Pacific had a major share and represented over $33 \%$ of worldwide supply in 2017.

The expanding research inputs and changing lifestyle along with an expanded patient pool experiencing nutrient inadequacy have been the key drivers in the development of the local market. Many of the Asian organizations are pivotal in creating a niche position in the Asia Pacific region. It is believed that solid application scope in nourishment and drinks will support territorial development. In Western Europe, many countries will observe noteworthy additions in the emerging market for vitamin K. It is believed that the UK will represent over $46 \%$ of the complete market by 2028 . Some of the key organizations involved in manufacturing and marketing are the BASF, Kyowa Hakko USA, DSM, Stason Pharmaceuticals, Frutarom, Pfizer, Bactolac Pharmaceutical Inc., Gene Farm Biotechnology Co., Ltd., Kappa Biosciences AS [89,91].

\section{CONCLUSION}

This review summarizes various aspects of vitamin $\mathrm{K}$, including its sources, health benefits, and market potential. Vitamin $\mathrm{K}$ is a popular vitamin important for blood coagulation. However, with the expansion of vitamin $\mathrm{K}$ series, it has become clear that vitamin $\mathrm{K} 1$ is a coagulation factor, while vitamin $\mathrm{K} 2$, which was previously not well understood, has gained a lot of impetus recently due to its multifaceted health benefits. It is now recognized as an essential nutraceutical in the management of osteoporosis, cardiac health diseases, diabetes, cancer, cognition, and pulmonary diseases and also has a role in modulating gene expression. Recently, its association in slowing the progression of COVID-19 has been noted. Now that it has got safety clearance from global agencies of Japan, US, and Europe, it is an accepted supplement for regulating calcium accumulation in bones and preventing soft tissue calcification. With the FDA approval, the vitamin K2 market has taken a sudden leap globally in the present decade and is expected to continue.

However, to meet the increasing demand, major focus should be on cost-effective production of Vitamin K2 where significant contribution can come from process engineers to develop microbial-based processes. At the same time, health practitioners and clinicians should continue to contribute toward its awareness and applications. Furthermore, more experimental studies need to be conducted to know the vitamin $\mathrm{K} 2$ action mechanism in management of various disease manifestations.

\section{AUTHOR CONTRIBUTIONS}

All authors made substantial contributions to conception and design, acquisition of data, or analysis and interpretation of data; took part in drafting the article or revising it critically for important intellectual content; agreed to submit to the current journal; gave final approval of the version to be published; and agree to be accountable for all aspects of the work. All the authors 
are eligible to be an author as per the international committee of medical journal editors (ICMJE) requirements/guidelines.

\section{FUNDING}

There is no funding to report.

\section{CONFLICT OF INTEREST}

The authors declare that they have no conflict of interest and no relationship and financial interest in any commercial companies referred to in this article.

\section{ETHICAL APPROVALS}

This study does not involve experiments on animals or human subjects.

\section{REFERENCES}

1. Dam H. Cholesterinstoffwechsel in Huhnereien und Huhnchen Biochem Zeitschr 1929;215:475-92.

2. Tsugawa N, Shiraki M. Vitamin K nutrition and bone health. Nutrients 2020;12(7):1909.

3. Oxholm Gordeladze J. Vitamin K2: a vitamin that works like a hormone, impinging on gene expression. In: Ray S (ed.). Cell Signalling-Thermodynamics and Molecular Control [Internet], IntechOpen, 2019. Available via https://www.intechopen.com/books/ cell-signalling-thermodynamics-and-molecular-control/vitamin-k2a-vitamin-that-works-like-a-hormone-impinging-on-gene-expression (Accessed 15 May 2021).

4. Xv F, Chen J, Duan L, Li S. Research progress on the anticancer effects of vitamin K2 (Review). Oncol Lett [Internet] 2018. Available via http:// www.spandidos-publications.com/10.3892/ol.2018.8502 (Accessed 15 May 2021).

5. Schwalfenberg GK. Vitamins K1 and K2: the emerging group of vitamins required for human health. J Nutr Metab 2017;2017:1-6.

6. Berenjian A, Mahanama R, Kavanagh J, Dehghani F. Vitamin K series: current status and future prospects. Crit Rev Biotechnol 2015;35(2):199-208.

7. Kojima A, Ikehara S, Kamiya K, Kajita E, Sato Y, Kouda K, et al. Natto intake is inversely associated with osteoporotic fracture risk in postmenopausal Japanese Women. J Nutr 2020;150(3):599-605.

8. DiNicolantonio JJ, Bhutani J, O'Keefe JH. The health benefits of vitamin K. Open Heart 2015;2(1):e000300.

9. w Walther B, Chollet M. Menaquinones, bacteria, and foods: vitamin $\mathrm{K} 2$ in the diet. In: Gordeladze JO (ed.). Vitamin K2-Vital for Health and Wellbeing [Internet], InTech, 2017. Available via http://www. intechopen.com/books/vitamin-k2-vital-for-health-and-wellbeing/ menaquinones-bacteria-and-foods-vitamin-k2-in-the-diet (Accessed 15 May 2021).

10. Shearer MJ, Newman P. Recent trends in the metabolism and cell biology of vitamin $\mathrm{K}$ with special reference to vitamin $\mathrm{K}$ cycling and MK-4 biosynthesis. J Lipid Res 2014;55(3):345-62.

11. Halder M, Petsophonsakul P, Akbulut A, Pavlic A, Bohan F, Anderson $\mathrm{E}$, et al. Vitamin $\mathrm{K}$ : double bonds beyond coagulation insights into differences between vitamin $\mathrm{K} 1$ and $\mathrm{K} 2$ in health and disease. IJMS 2019;20(4):896

12. Okano T, Shimomura Y, Yamane M, Suhara Y, Kamao M, Sugiura M, et al. Conversion of phylloquinone (vitamin K1) into menaquinone-4 (vitamin K2) in mice. J Biol Chem 2008;283(17):11270-9.

13. Hirota Y, Tsugawa N, Nakagawa K, Suhara Y, Tanaka K, Uchino $\mathrm{Y}$, et al. Menadione (vitamin K3) is a catabolic product of oral phylloquinone (vitamin K1) in the intestine and a circulating precursor of tissue menaquinone-4 (vitamin K2) in rats. J Biol Chem 2013;288(46):33071-80.
14. Simes DC, Viegas CSB, Araújo N, Marreiros C. Vitamin K as a diet supplement with impact in human health: current evidence in agerelated diseases. Nutrients 2020;12(1):138.

15. Ayombil F, Camire RM. Insights into vitamin K-dependent carboxylation: home field advantage. Haematologica 2020;105(8): 1996-8.

16. Akbari S, Rasouli-Ghahroudi AA. Vitamin K and bone metabolism: a review of the latest evidence in preclinical studies. BioMed Rese Int 2018;2018:1-8.

17. Liu S, Li S, Shen G, Sukumar N, Krezel AM, Li W. Structural basis of antagonizing the vitamin $\mathrm{K}$ catalytic cycle for anticoagulation. Science 2021;371(6524):eabc5667.

18. Jones DA, Wright P, Alizadeh MA, Fhadil S, Rathod KS, Guttmann O, et al. The use of novel oral anti-coagulant's (NOAC) compared to vitamin $\mathrm{K}$ antagonists (Warfarin) in patients with left ventricular thrombus after acute myocardial infarction (AMI). Eur Heart J Cardiovasc Pharmacother 2020; pvaa096; doi:10.1093/ehjcvp/pvaa096

19. Akbulut AC, Pavlic A, Petsophonsakul P, Halder M, Maresz K, Kramann R, et al. Vitamin K2 needs an RDI separate from vitamin K1. Nutrients 2020;12(6):1852.

20. Braasch-Turi M, Crans DC. Synthesis of naphthoquinone derivatives: menaquinones, lipoquinones and other vitamin $\mathrm{K}$ derivatives. Molecules 2020;25(19):4477.

21. Song J, Liu H, Wang L, Dai J, Liu Y, Liu H, et al. Enhanced production of vitamin $\mathrm{K} 2$ from Bacillus subtilis (natto) by mutation and optimization of the fermentation medium. Braz Arch Biol Technol 2014;57(4):606-12.

22. Wu WJ, Ahn BY. Statistical optimization of medium components by response surface methodology to enhance menaquinone-7 (vitamin K2) production by Bacillus subtilis. J Microbiol Biotechnol 2018;28(6):902-8.

23. Ren L, Peng C, Hu X, Han Y, Huang H. Microbial production of vitamin K2: current status and future prospects. Biotechnol Adv 2020;39:107453.

24. Bøe CA, Holo H. Engineering Lactococcus lactis for increased vitamin K2 production. Front Bioeng Biotechnol 2020;8:191.

25. Kamao M, Suhara Y, Tsugawa N, Uwano M, Yamaguchi N, Uenishi $\mathrm{K}$, et al. Vitamin $\mathrm{K}$ content of foods and dietary vitamin $\mathrm{K}$ intake in Japanese young women. J Nutr Sci Vitaminol 2007;53(6):464-70.

26. Walther B, Karl JP, Booth SL, Boyaval P. Menaquinones, bacteria, and the food supply: the relevance of dairy and fermented food products to vitamin K requirements. Adv Nutr 2013;4(4):463-73.

27. Geleijnse JM, Vermeer C, Grobbee DE, Schurgers LJ, Knapen MHJ, van der Meer IM, et al. Dietary intake of menaquinone is associated with a reduced risk of coronary heart disease: the rotterdam study. J Nutr 2004;134(11):3100-5.

28. McCann JC, Ames BN. Vitamin K, an example of triage theory: is micronutrient inadequacy linked to diseases of aging? Am J Clin Nutr 2009;90(4):889-907.

29. Tutusaus A, Marí M, Ortiz-Pérez JT, Nicolaes GAF, Morales A, García de Frutos P. Role of vitamin K-dependent factors protein $\mathrm{S}$ and GAS6 and TAM receptors in SARS-CoV-2 infection and COVID-19associated immunothrombosis. Cells 2020;9(10):2186.

30. Jagannath VA, Thaker V, Chang AB, Price AI. Vitamin K supplementation for cystic fibrosis. Cochrane Database Syst Rev [Internet] 2020; doi:10.1002/14651858.CD008482.pub6 (Accessed 17 May 2021).

31. Katayama T, Yokoyama N, Hirofumi H, Kataoka A, Watanabe Y, Kozuma K. Blood coagulation status after transcatheter aortic valve implantation between the patients with vitamin $\mathrm{K}$ antagonist and direct oralanticoagulants.EurHeartJ2020;41(Supplement_2):ehaa946.1992.

32. Al-Suhaimi EA, Al-Jafary MA. Endocrine roles of vitamin $\mathrm{K}$-dependent- osteocalcin in the relation between bone metabolism and metabolic disorders. Rev Endocr Metab Disord 2020;21(1): $117-25$. 
33. Shetty S, Kapoor N, Bondu JD, Thomas N, Paul TV. Bone turnover markers: emerging tool in the management of osteoporosis. Indian $\mathrm{J}$ Endocrinol Metab 2016;20(6):846.

34. Vermeer C, Theuwissen E. Vitamin K, osteoporosis and degenerative diseases of ageing. Menopause Int 2011;17(1):19-23.

35. Knapen MHJ, Drummen NE, Smit E, Vermeer C, Theuwissen E. Three-year low-dose menaquinone-7 supplementation helps decrease bone loss in healthy postmenopausal women. Osteoporos Int 2013;24(9):2499-507.

36. Singh S. Serum osteocalcin as a diagnostic biomarker for primary osteoporosis in women. JCDR [Internet] 2015. Available via http:// jcdr.net/article_fulltext.asp?issn $=0973-709 x \& y e a r=2015 \&$ volume $=$ 9\&issue $=8 \&$ page $=$ RC04\&issn $=0973-709 x \& i d=6318$ (Accessed 18 May 2021).

37. Azuma K, Inoue S. Multiple modes of vitamin $\mathrm{K}$ actions in agingrelated musculoskeletal disorders. Int J Mol Sci 2019;20(11):2844.

38. Bolton-Smith C, McMurdo ME, Paterson CR, Mole PA, Harvey JM, Fenton ST, et al. Two-year randomized controlled trial of vitamin K1 (phylloquinone) and vitamin D3 plus calcium on the bone health of older women. J Bone Miner Res 2007;22(4):509-19.

39. Cockayne S, Adamson J, Lanham-New SL, Shearer MJ, Gilbody S, Torgerson DJ. Vitamin K and the prevention of fractures: systematic review and meta-analysis of randomized controlled trials. Arch Intern Med 2006;166(12):1256-61; doi:10.1001/archinte.166.12.1256

40. Ishida Y. Vitamin K2. Clin Calcium 2008;18(10):1476-82.

41. Pearson K. Vitamin K1 vs. K2: what's the difference? [Internet]. Healthline 2017. Available via https://www.healthline.com/nutrition/ vitamin-k1-vs-k2 (Accessed 18 May 2021).

42. van Ballegooijen AJ, Pilz S, Tomaschitz A, Grübler MR, Verheyen $\mathrm{N}$. The synergistic interplay between vitamins $\mathrm{D}$ and $\mathrm{K}$ for bone and cardiovascular health: a narrative review. Int $\mathrm{J}$ Endocrinol 2017;2017:1-12.

43. Beulens JWJ, Bots ML, Atsma F, Bartelink MLEL, Prokop M, Geleijnse JM, et al. High dietary menaquinone intake is associated with reduced coronary calcification. Atherosclerosis 2009;203(2):489-93.

44. Theuwissen E, Smit E, Vermeer C. The role of vitamin K in soft-tissue calcification. Adv Nutr 2012;3(2):166-73.

45. Raggi P, Boulay A, Chasan-Taber S, Amin N, Dillon M, Burke SK, et al. Cardiac calcification in adult hemodialysis patients. J Am Coll Cardiol 2002;39(4):7.

46. Schurgers LJ, Spronk HMH, Skepper JN, Hackeng TM, Shanahan $\mathrm{CM}$, Vermeer $\mathrm{C}$, et al. Post-translational modifications regulate matrix Gla protein function: importance for inhibition of vascular smooth muscle cell calcification. J Thromb Haemost 2007;5(12):2503-11.

47. Schurgers LJ, Cranenburg ECM, Vermeer C. Matrix Gla-protein: the calcification inhibitor in need of vitamin K. Thromb Haemost 2008;100(4):593-603.

48. Lindholt JS, Frandsen NE, Fredgart MH, Øvrehus KA, Dahl JS, Møller $\mathrm{JE}$, et al. Effects of menaquinone-7 supplementation in patients with aortic valve calcification: study protocol for a randomised controlled trial. BMJ Open 2018;8:e22019; doi:10.1136/bmjopen-2018-022019

49. Shioi A, Morioka T, Shoji T, Emoto M. The inhibitory roles of vitamin $\mathrm{K}$ in progression of vascular calcification. Nutrients [Internet] 2020;12(2). Available via https://www.ncbi.nlm.nih.gov/pmc/articles/ PMC7071387/ (Accessed 18 May 2021).

50. Vermeer CV. Vitamin K: the effect on health beyond coagulation - an overview. Food Nutr Res 2012;56(1):5329.

51. Cozzolino M, Cianciolo G, Podestà MA, Ciceri P, Galassi A, Gasperoni $\mathrm{L}$, et al. Current therapy in CKD patients can affect vitamin $\mathrm{K}$ status. Nutrients 2020;12(6):1609.

52. Ho HJ, Komai M, Shirakawa H. Beneficial effects of vitamin K status on glycemic regulation and diabetes mellitus: a mini-review. Nutrients 2020;12(8):1-16.

53. Li Y, Chen JP, Duan L, Li S. Effect of vitamin K2 on type 2 diabetes mellitus: a review. Diabetes Res Clin Pract 2018;136:39-51.
54. Choi HJ, Yu J, Choi H, An JH, Kim SW, Park KS, et al. Vitamin K2 supplementation improves insulin sensitivity via osteocalcin metabolism: a placebo-controlled trial. Diabetes Care 2011;34(9):e147.

55. Hussein AG, Mohamed RH, Shalaby SM, Abd El Motteleb DM. Vitamin $\mathrm{K} 2$ alleviates type 2 diabetes in rats by induction of osteocalcin gene expression. Nutrition 2018;47:33-8.

56. Ferron M, Hinoi E, Karsenty G, Ducy P. Osteocalcin differentially regulates beta cell and adipocyte gene expression and affects the development of metabolic diseases in wild-type mice. Proc Natl Acad Sci U S A 2008;105(13):5266-70.

57. Bourron O, Phan F. Vitamin K: a nutrient which plays a littleknown role in glucose metabolism. Curr Opin Clin Nutr Metab Care 2019;22(2):174-81.

58. Ichikawa T, Horie-Inoue K, Ikeda K, Blumberg B, Inoue S. Vitamin $\mathrm{K} 2$ induces phosphorylation of protein kinase $\mathrm{A}$ and expression of novel target genes in osteoblastic cells. J Mol Endocrinol 2007;39(4): 239-47.

59. Ito A, Shirakawa H, Takumi N, Minegishi Y, Ohashi A, Howlader ZH, et al. Menaquinone- 4 enhances testosterone production in rats and testis-derived tumor cells. Lipids Health Dis 2011;10(1):158.

60. NTVitamin K2 boosts testosterone-JornTrommelen.com [Internet]. 2011. Available via https://www.nutritiontactics.com/vitamin-k2boosts-testosterone/ (Accessed 17 May 2021).

61. Sanyaolu AO, Oremosu AA, Osinubi AA, Vermeer C, Daramola AO. Warfarin-induced vitamin $\mathrm{K}$ deficiency affects spermatogenesis in Sprague-Dawley rats. Andrologia 2019;51(10):13416.

62. Shiba S, Ikeda K, Horie-Inoue K, Azuma K, Hasegawa T, Amizuka N, et al. Vitamin K-dependent $\gamma$-glutamyl carboxylase in Sertoli cells is essential for male fertility in mice. Mol Cell Biol 2021;41(4).

63. Popa DS, Bigman G, Rusu ME. the role of vitamin K in humans: implication in aging and age-associated diseases. Antioxidants 2021;10(4):566.

64. Kakizaki S, Sohara N, Sato K, Suzuki H, Yanagisawa M, Nakajima H, et al. Preventive effects of vitamin $\mathrm{K}$ on recurrent disease in patients with hepatocellular carcinoma arising from hepatitis $\mathrm{C}$ viral infection. J Gastroenterol Hepatol 2007;22(4):518-22.

65. Beaudin S, Kokabee L, Welsh J. Divergent effects of vitamins $\mathrm{K} 1$ and $\mathrm{K} 2$ on triple negative breast cancer cells. Oncotarget 2019;10(23):2292-305; doi:10.18632/oncotarget.26765

66. Ivanova D, Zhelev Z, Getsov P, Nikolova B, Aoki I, Higashi T, et al. Vitamin $\mathrm{K}$ : redox-modulation, prevention of mitochondrial dysfunction and anticancer effect. Redox Biol 2018;16:352-8.

67. Dahlberg S, Ede J, Schött U. Vitamin K and cancer. Scand J Clin Lab Invest 2017;77(8):555-67.

68. Verrax J, Taper H, Buc Calderon P. Targeting cancer cells by an oxidant-based therapy. Curr Mol Pharmacol 2008;1(1):80-92.

69. Yokoyama T, Miyazawa K, Naito M, Toyotake J, Tauchi T, Itoh M, et al. Vitamin K2 induces autophagy and apoptosis simultaneously in leukemia cells. Autophagy 2008;4(5):629-40.

70. Duan F, Mei C, Yang L, Zheng J, Lu H, Xia Y, et al. Vitamin K2 promotes PI3K/AKT/HIF-1 $\alpha$-mediated glycolysis that leads to AMPK-dependent autophagic cell death in bladder cancer cells. Sci Rep 2020;10(1):7714.

71. Ferland G. Vitamin K and the nervous system: an overview of its actions. Adv Nutr 2012;3(2):204-12.

72. Shearer MJ, Fu X, Booth SL. Vitamin K nutrition, metabolism, and requirements: current concepts and future research. Adv Nutr 2012;3(2):182-95.

73. Gancheva SM,Zhelyazkova-Savova MD. Vitamin K2 improves anxiety and depression but not cognition in rats with metabolic syndrome: a role of blood glucose? Folia Med (Plovdiv) 2016;58(4):264-72.

74. Huang SH, Fang ST, Chen YC. Molecular mechanism of vitamin $\mathrm{K} 2$ protection against amyloid- $\beta$-induced cytotoxicity. Biomolecules 2021;11(3):423.

75. Yu YX, Yu XD, Cheng QZ, Tang L, Shen MQ. The association of serum vitamin K2 levels with Parkinson's disease: from basic case- 
control study to big data mining analysis. Aging (Albany NY) 2020;12(16):16410-9.

76. Lin X, Wen X, Wei Z, Guo K, Shi F, Huang T, et al. Vitamin K2 protects against $\mathrm{A} \beta 42$-induced neurotoxicity by activating autophagy and improving mitochondrial function in Drosophila. Neuroreport 2021;32(6):431-7.

77. Tanprasertsuk J, Ferland G, Johnson MA, Poon LW, Scott TM, Barbey $\mathrm{AK}$, et al. Concentrations of circulating phylloquinone, but not cerebral menaquinone-4, are positively correlated with a wide range of cognitive measures: exploratory findings in centenarians. J Nutr 2020;150(1):82-90.

78. Tamadon-Nejad S, Ouliass B, Rochford J, Ferland G. Vitamin K deficiency induced by warfarin is associated with cognitive and behavioral perturbations, and alterations in brain sphingolipids in rats. Front Aging Neurosci [Internet] 2018;10. Available via https://www. frontiersin.org/articles/10.3389/fnagi.2018.00213/full (Accessed 2 June 2021)

79. Shen T, Bimali M, Faramawi M, Orloff MS. Consumption of vitamin $\mathrm{K}$ and vitamin $\mathrm{A}$ are associated with reduced risk of developing emphysema: NHANES 2007-2016. Front Nutr [Internet] 2020;7. Available via https://www.frontiersin.org/articles/10.3389/ fnut.2020.00047/full (Accessed 2 June 2021).

80. Linneberg A, Kampmann FB, Israelsen SB, Andersen LR, Jørgensen HL, Sandholt $\mathrm{H}$, et al. Low vitamin $\mathrm{K}$ status predicts mortality in a cohort of 138 hospitalized patients with COVID-19. medRxiv [Internet].. Available via https://www.medrxiv.org/ content/10.1101/2020.12.21.20248613v1 (Accessed 2 June 2021).

81. Janssen R, Visser MPJ, Dofferhoff ASM, Vermeer C, Janssens W, Walk J. Vitamin K metabolism as the potential missing link between lung damage and thromboembolism in Coronavirus disease 2019. Br J Nutr 2020;1-8.

82. Dofferhoff ASM, Piscaer I, Schurgers LJ, Visser MPJ, van den Ouweland JMW, de Jong PA, et al. Reduced vitamin K status as a potentially modifiable risk factor of severe coronavirus disease 2019 . Clin Infect Dis 2020; ciaa1258.

83. Goddek S. Vitamin D3 and K2 and their potential contribution to reducing the COVID-19 mortality rate. Int J Infect Dis 2020;99:286-90.

84. Nishiga M, Wang DW, Han Y, Lewis DB, Wu JC. COVID-19 and cardiovascular disease: from basic mechanisms to clinical perspectives. Nat Rev Cardiol 2020;17(9):543-58.

85. WHO. Global atlas on cardiovascular disease prevention and control [Internet]. WHO, Geneva, Switzerland. Available via http://www.who. int/cardiovascular_diseases/publications/atlas_cvd/en/ (Accessed 20 May 2021).
86. Global vitamin K market size analysis and industry opportunityBekryl market analysts [Internet]. Available via https://bekryl. com/industry-trends/vitamin-k-market-size-analysis (Accessed 20 May 2021).

87. Pucaj K, Rasmussen H, Møller M, Preston T. Safety and toxicological evaluation of a synthetic vitamin K2, menaquinone-7. Toxicol Mech Methods 2011;21(7):520-32.

88. Quinlan PTURV. Vitamin K2 containing food product [Internet]. EP1153548A1, 2001. Available via https://patents.google.com/patent/ EP1153548A1/en (Accessed 22 May 2021).

89. Inc GMI. Vitamin K Market value to hit $\$ 1$ billion by 2025: Global Market Insights, Inc. [Internet]. GlobeNewswire News Room. 2019. Available via https://www.globenewswire.com/en/news-release/2019/08/13/1900907/0/ en/Vitamin-K-Market-value-to-hit-1-billion-by-2025-Global-MarketInsights-Inc.html (Accessed 20 May 2021).

90. Vitamin K market size, share, growth, trend, demand, top players, opportunities and forecast to 2025-MarketWatch [Internet]. Available via https://www.marketwatch.com/press-release/vitamink-market-size-share-growth-trend-demand-top-players-opportunitiesand-forecast-to-2025-2021-05-19?tesla=y (Accessed 20 May 2021).

91. Vitamin K2 Market 2019: deep analysis of current trends and future demand by top key players are DSM, Kyowa Hakko, GeneFerm Biotechnology Co., Ltd., Frutarom, Kappa Bioscience AS. Medgadget [Internet]. Available via https://www.medgadget.com/2019/09/ vitamin-k2-market-2019-deep-analysis-of-current-trends-and-futuredemand-by-top-key-players-are-dsm-kyowa-hakko-genefermbiotechnology-co-ltd-frutarom-kappa-bioscience-as.html (Accessed 19 May 2021).

\section{How to cite this article:}

Aggarwal S, Gupta S, Sehgal S, Srivastava P, Sen A, Gulyani G, Jain A. Vitamin K2: An emerging essential nutraceutical and its market potential. J Appl Biol Biotech 2022; 10(02): 173-184 